\title{
Characterization of Phospholipid Polymer Hydrogel for Immobilization Enzyme
}

\author{
Jun Yamaguchi, Tomohiro Konno, Madoka Takai, Kazuhiko Ishihara* \\ Department of Materials Engineering, School of Engineering and Center for NanoBio Integration,
}

The University of Tokyo

\author{
7-3-1, Hongo, Bunkyou-ku, Tokyo 113-8656, Japan \\ Fax : +81-3-5841-8647, e-mail : ishihara@mpc.t.u-tokyo.ac.jp
}

To construct polymer hydrogel microstructure containing biomolecules as a biosensor in microfluidic devices by a conventional photoirradiation, new photocrosslinkable polymers composed of 4-(4methoxycinnamoyl)phenyl methacrylate and 2-methacryloyloxyethyl phosphorylcholine (PMMC) was synthesized. The polymers were used as prepolymers to make hydrogels by photoiradiation. Moreover, PMMC gel exhibited excellent performance of protein adsorption resistance compared with Poly(vinyl alcohol)- $N$-methyl-4(4'-formylstyryl) pyridinium methosulfate acetal (PVA-SbQ), and succeeded in the immobilizing of enzyme. In the future, the immobilized enzyme will be checked in detail for application of PMMC to a biosensor. PMMC is thought to be increasing the permeability of the biomolecules to the inside of the gel compared with PVA-SbQ which is the material commonly used in the current researches. From the results so far, it is expected that PMMC can be used for simple fabrication of enzyme immobilizing membranes for highly sensitive biosensors.

Key words: photocrosslinkable phospholipid polymer, hydrogel, biocompatibility, microfabrication, enzyme immobilization

\section{INTRODUCTION}

The photochemical reactions of polymers have been paid strong attention not only for photoresist application in electronic field but also for photofabrication of microbiodevices in modern bioengineering field [1-3] because of several advantages they have such as rapid and homogeneous reactions could be proceeded at room temperature. Moreover, microfabrication by the photochemical reactions can be carried out more efficiently in comparing with normal chemical and physical techniques.

Recently, by using the photocrosslinking reaction between polymer chains, several microstractures are constructed in the microfluidics on a biochip, which are gate, valve, salt-bridge, and immobilized biocomponents including proteins, DNA, and cells. Polymers, in general, used in these purposes are polysaccharide, polypeptide and hydrophilic synthetic polymers [4-10]. Most of them use photopolymerization system composed of monomer, crosslinker and initiator for radical generation by photoirradiation. Jiménez et al. reported the photopolymerization of acrylamide for enzymatic microsensor fabrication [11]. It was a successful method, however, sometimes the remaining monomer and photoinitiator disturbed enzymatic reactions and radicals generated from the photopolymerization attacked enzyme and induced significant reduction of activity of immobilized enzyme in the polymer matrix. Thus, polymer-type photocrosslinker have been investigated. Some photochemical reactive groups should be introduced in the polymer chains. Although there are many photochemical reactions, photoinduced dimerization is considerably suitable for making crosslinking points in biomedical hydrogels [5,12-14]. Because of the absence of byproduct during the reaction, biomolecules immobilized in the hydrogel may maintain their activities. PVA-SbQ known as photocrosslinkable polymer has been put to practical use in immobilization of enzymes [12]. The PVA-SbQ is a hydrophilic polymer and forms a hydrogel by photoirradiation. In general, PVA is believed as a biocompatible polymer, but, considerable protein adsorption was observed at the surface and clot formation was induced in shortly. That is, when the surface of the biosensor was covered with the PVA membrane and the sensor was implanted subcutaneously, the sensor 


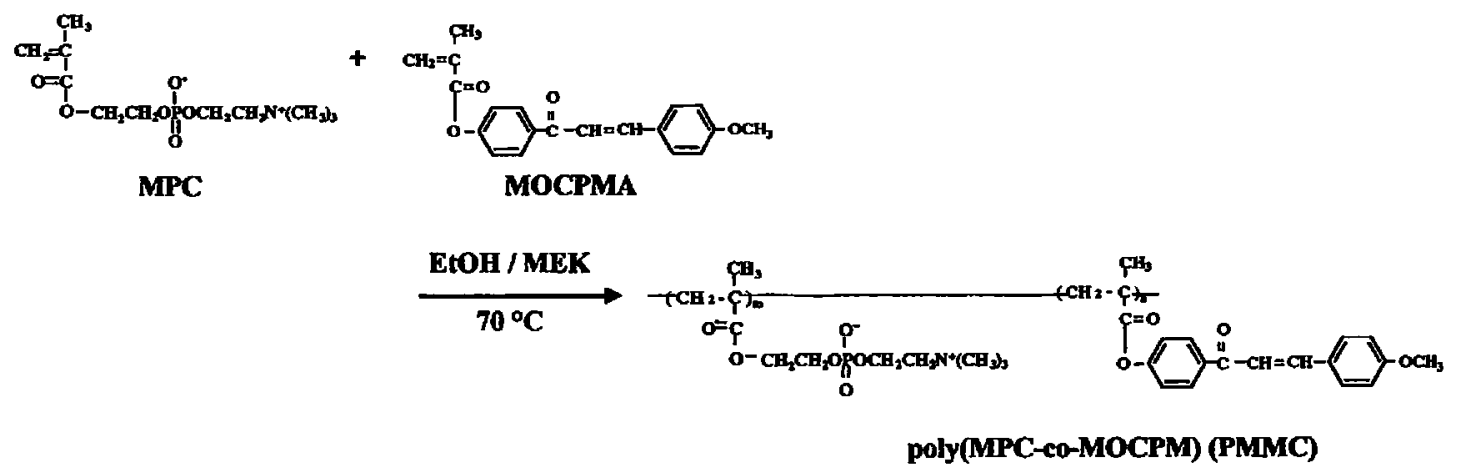

Figure 1: Synthesis of poly(MPC-co-MOCPMA) (PMMC).

output decreased with time dramatically due to protein adsorption [13]. Moreover, $\operatorname{poly}(N-$ isopropylacrylamide) having stilbazolium had also been reported [14]. In case of microfabrication of microfluidics on biochip, the condition may be much more severe because the amount of target biological components is quite low in the microfluidics. Therefore, to inhibit the nonspecific adsorption of these biocomponents should be required. Fortunately, in our current research for biocompatible polymers, the polymers bearing phosphorylcholine groups showed excellent performance of protein adsorption resistance and cell adhesion inhibition [15-20]. These polymers are composed of 2methacryloyloxyethyl phosphorylcholine (MPC) and other vinyl compounds. The MPC copolymers have extremely hydrophilic and hydrogel structure can be expected using suitable crosslinkers.

In this study, to obtain hydrogel by photoirradiation, we synthesized polymers composed of the MPC and 4-(4methoxycinnamoyl) phenyl methacrylate (MOCPMA). The MOCPMA unit is expected to form crosslinking points through photodimerization process of cinnamoyl groups [21]. In previous research, the synthesis of the hydrogel by photoirradiation using photocrosslinkable phospholipids polymer had been successfully carried out. The equilibrium water contents (EWCs) of the obtained hydrogels were more than $90 \%$. Moreover, the microfabrication of the hydrogel by micropatterning using the photomask was also successfully conducted and the microfabricated hydrogel was swollen by water as well as hydrogel synthesized by mold plates [22,23]. Here, we report the characterization of the MPC polymer hydrogel as the matrix for enzyme immobilization formed by photoirradiation.

\section{MATERIALS and METHODS}

\subsection{Materials}

The MPC was synthesized by the method previously reported [24]. 4Hydroxyacetophenone, 4-methoxybenzaldehyde, and 2,2'-azobisisobutyronitrile (AIBN) were purchased from Kanto Kagaku (Tokyo, Japan), respectively, and were used as received. Glucose oxidase (GOD) of Aspergillus niger $(210 \mathrm{U} / \mathrm{mg}$ ) and Peroxidase (POD) from Horseradish were purchased from Wako Pure Chemical (Osaka, Japan). Other organic reagents and solvents were purified by the usual method.

\subsection{Synthesis of polymers}

4-(4-Methoxycinnamoyl)phenyl methacrylate (MOCPMA) was synthesized as previously described by Reddy et al. [25]. Random copolymers of MPC and MOCPMA were synthesized by copolymerization in ethanol (EtOH)/methyl ethyl ketone (MEK) mixtures, using 2,2'-azobisisobutyronitrile (AIBN) as an initiator. The concentration of monomer to the solvent was $0.2 \mathrm{~mol} / \mathrm{L}$. The initiator concentration was 1 mol\% of the total monomers. The polymerization was carried out with stirring at $70{ }^{\circ} \mathrm{C}$ for $2 \mathrm{~h}$ in argon atmosphere. The polymers obtained were precipitated from large excess of diethyl ether/chloroform (50/50 in volume). The polymers were characterized by using ${ }^{1}$ H-NMR spectroscopy and GPC. We prepared various polymers with different MPC unit composition [23]. However, due to solubility in water and reactivity by photoirradiation, we use a polymer with $90 \mathrm{~mol} \%$ MPC unit (PMMC90) in this study.

\subsection{Protein adsorption of PMMC90 gel}

The EtOH solution containing 20-wt\% PMMC90 was spincoated (500 rpm for $5 \mathrm{sec}$ and $2000 \mathrm{rpm}$ for $20 \mathrm{sec}$ ) on the glass substrate. After drying up, it was exposed with light for $\mathbf{6 0}$ 
Table 1. Characterization of PMMC.

\begin{tabular}{|c|c|c|c|c|c|c|c|c|}
\hline & \multicolumn{2}{|c|}{ Monomer composition (mol\%) } & \multicolumn{2}{|c|}{ Compostion in topolymer ${ }^{2)}$ (mol\%) } & \multirow[b]{2}{*}{$M_{W}^{\text {b) }}\left(\times 10^{-4}\right)$} & \multirow[b]{2}{*}{ Yield (\%) } & \multicolumn{2}{|c|}{ Solubility of } \\
\hline & MPC & MOCPMA & MPC & MOCPMA & & & in EtOH & in water \\
\hline PMMC90 & 90 & 10 & 91 & 9 & 2.9 & 79 & + & + \\
\hline $\begin{array}{l}{[\mathrm{M}]=0.2 \mathrm{n}} \\
\text { Polymerix } \\
\text { Polymeriz }\end{array}$ & $\begin{array}{l}\text { W/L, [AIB } \\
\text { ion time } \\
\text { ion temp }\end{array}$ & $\begin{array}{l}]_{2 h}=2 \mathrm{mmol} / \mathrm{L} \\
2 \mathrm{~h} \\
\text { ature }=70^{\circ} \mathrm{C}\end{array}$ & $\begin{array}{l}\text { a)Detern } \\
\text { b) Deter } \\
\text { poly(et } \\
\text { c) Solubi }\end{array}$ & $\begin{array}{l}\text { red by 1H-NMR. } \\
\text { ned by GPC in w8 } \\
\text { lene glychol) stan } \\
\text { was determined }\end{array}$ & $1 \mathrm{mg} / \mathrm{ml} \mathrm{po}$ & $\begin{array}{l}\text { /7, } \\
\text { ner e }\end{array}$ & tration. & \\
\hline
\end{tabular}

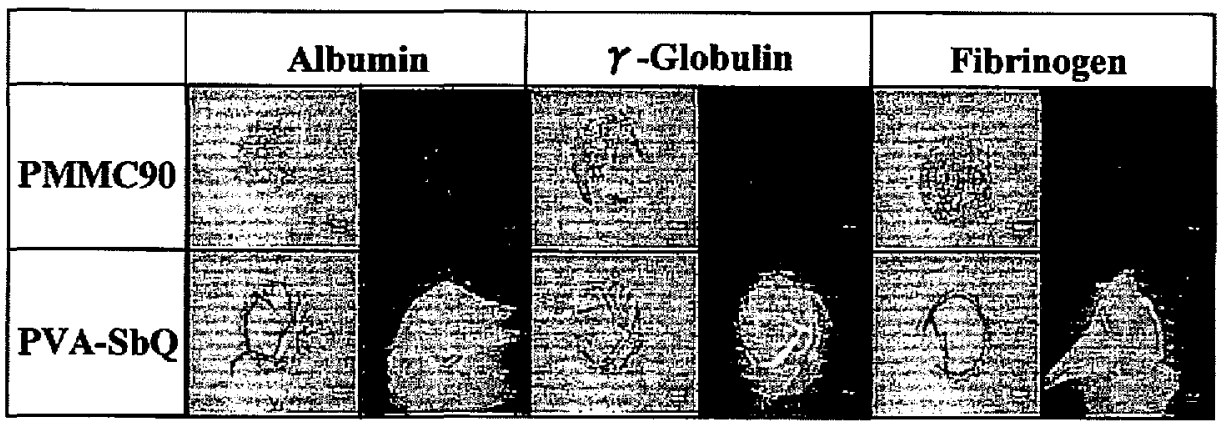

Figure 2: Images of protein adsorption on PMMC90 and PVA-SbQ taken by fluorescence microscope.

sec through a photomask having a circle structure pattern $(0.3 \mathrm{~mm}$ in diameter) at room temperature. Then the polymer on the substrate was washed with EtOH to remove the unreacted polymer. The hydrogels were immersed in FITC-labeled $(\lambda \mathrm{ex}=490 \mathrm{~nm}, \lambda \mathrm{em}=520 \mathrm{~nm})$ protein $(4.5 \mathrm{mg} / \mathrm{mL}$ albumin, $1.3 \mathrm{mg} / \mathrm{mL} \quad \gamma$-Globulin or $0.3 \mathrm{mg} / \mathrm{mL}$ Fibrinogen) in PBS solution at $37^{\circ} \mathrm{C}$ for 1 hour, and then rinsed twice with stirring method in fresh PBS for $5 \mathrm{~min}$. The concentrations of proteins were $10 \%$ of the plasma concentration. The obtained hydrogels were observed by fluorescence microscope. The protein adsorption of hydrogels was calculated from fluorescence intensity by fluorescence image scanner (Typhoon 9410). A similar operation was carried out in PVA-SbQ.

\subsection{GOD immobilization in PMMC90 gel}

A mixture of $20 w t \% P M M C$ and GOD aqueous solution (PMMC90: GOD $=10: 1$ ) was spreaded on petri dish. After reduced pressure drying, the photoirradiation was conducted for 1 hour. The GOD-immobilized PMMC90gel obtained was then rinsed with water. The color identification test of the GOD in the hydrogel was carried out by using reactive solution $(0.2 \mathrm{mmol} / \mathrm{L}$ o-Dianisidine aqueous solution : $24 \mathrm{~mL}, 5 \mathrm{mg} / \mathrm{mL}$ POD aqueous solution : $1 \mathrm{~mL}$ and $100 \mathrm{mg} / \mathrm{mL}$ glucose aqueous solution : $5 \mathrm{~mL}$ ).

\section{RESULTS AND DISCUSSION \\ 3.1 Synthesis of PMMC}

The photoreactive MPC polymer (PMMC90)

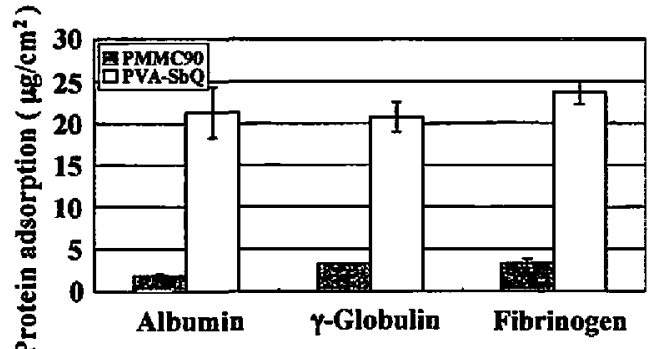

Figure 3: Protein adsorption of PMMC90 and PVA-SbQ calculated from fluorescence intensity.

was synthesized. The results of polymerization and molecular characteristics of the polymer are summarized in Table 1. The PMMC90 is soluble in water.

\subsection{Protein adsorption of PMMC gel}

Figure 2 shows images of protein adsorption in PMMC90 and PVA-SbQ taken by fluorescence microscope. It can be confirmed that PVA-SbQ showed high fluorescent strength compared with PMMC90. Figure 3 shows protein adsorption of PMMC90 and PVA-SbQ calculated from fluorescence intensity. As from this result, it was confirmed that PMMC90 shows excellent performance of protein adsorption resistance compared with PVA-SbQ used as a past enzyme immobilization membrane. 
3.3 GOD immobilization in PMMC90

Figure 4 shows enzymatic reaction of GOD immobilized PMMC90. When the GODimmobilized PMMC90geI was soused the reactive solution, it was checked to have changed PMMC90 into brown as the indication of that GOD was immobilized to PMMC90 without changing its activity.

Therefore, it was confirmed that PMMC90 is applied to the enzyme immobilization matrix as well as the PVA-SbQ.

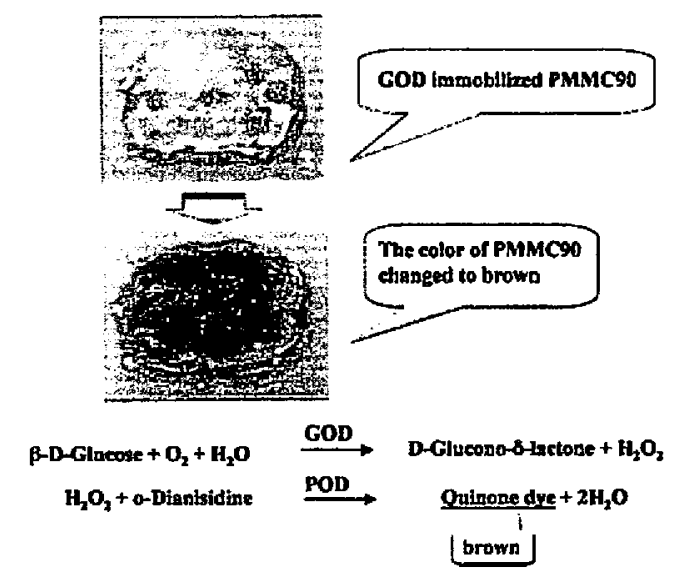

Figure 4: Enzymatic reaction of GOD immobilized PMMC90.

\section{CONCLUSION}

New photocrosslinkable polymers having both phosphorylcholine and cinnamoyl groups have been synthesized successfully. The polymers were used as prepolymers to make hydrogels by photoirradiation. The microfabricated PMMC90 gel on a glass substrate exhibited excellent performance of protein adsorption resistance compared with that observed on the PVA-SbQ. Moreover, GOD can be immobilized in the PMMC90 gel maintaining its activity.

In the future, the immobilized enzyme will be detaily investigated for application of PMMC to a biosensor. PMMC is thought to be increasing the permeability of the biomolecules to the inside of the gel compared with PVA-SbQ which is the material commonly used in the current researches. From the results so far, it is expected that the PMMC can be used for simple fabrication of enzyme immobilizing matrix for highly sensitive biosensors instead of PVA-SbQ.

\section{REFERENCES}

[1] D. J. Beebe, J. M. Bauer, Q. Yu, R. H. Liu, C. Devadoss, B. H. Jo, Nature, 404, 588-590 (2000). [2] Y. Takamura, H. Onoda, H. Inokuchi, S. Adachi, A. Oki, Y. Horiike, Electrophoresis, 24, 185-192 (2003).
[3] V. M. Nivasu, T. T. Reddy; S. Tammishetti, Biomaterials, 25, 3283-3291 (2004).

[4] K. A. Smeds, M. W. Grinstaff, J. Biomed. Mater. Res., 54, 115 (2001).

[5] Y. Nakayama, T. Matsuda J. Polym. Sci. Part A: Polym. Chem. 30, 977 (1993)

[6] N. Vyavahare, J. Kohn, J. Polym. Sci. Part A: Polym. Chem., 32, 1271 (1994)

[7] H. Okino; Y. Nakayama; M. Tanaka; T. Matsuda, J. Biomed. Mater. Res., 59, 233 (2002)

[8] H. Simburger, W. Kern, K. Hummel, C. Hagg, Polymer, 22, 7883 (2000)

[9] R. Balaji, S. Nanjundan, J. Appl. Polym. Sci., 24, 1023 (2002)

[10] Y. Nakayama, T. Matsuda, J. Appl. Polym. Sci., 31, 3299 (1993)

[11] C. Jiménez, J. Bartrol, N. F. de Rooij, M. Koudelka-Hep, Analytica Chimica Acta, 351, 1-3, 169 (1997)

[12] K. Ichimura, J. Polym. Sci., Polym. Chem. Ed., 22, 2817 (1984)

[13] M. Sakakida, K. Nishida, M. Shichiri, K. Ishihara, N. Nakabayashi, Sensors and Actuators $B, 13-14,319$ (1993)

[14] J. Hoffmann, M. Plotner, D. Kuckling, W. Fischer, Sensors and Actuators A, 77, 139 (1999)

[15] K. Ishihara, N. P. Ziats, B. P. Tierney, N. Nakabayashi; J. M. Anderson, $J$. Biomed. Mater. Res., 25, 1397 (1991)

[16] K. Ishihara, H. Oshida, T. Ueda, Y. Endo, N. Nakabayashi, J. Biomed. Mater. Res., 26, 1543 (1992)

[17] K. Ishihara, E. Ishikawa, Y. Iwasaki, N. Nakabayashi, J. Biomater. Sci., Polymer Edn., 10 (10), 1047 (1999)

[18] K. Ishihara, D. Nishiuchi, J. Watanabe, Y. Iwasaki, Biomaterials, 25(4), 1115 (2004)

[19] J. Patel, Y. Iwasaki, K.;Ishihara, J. Anderson, J. Biomed. Mater. Res., 73A, 359 (2005)

[20] W. Feng, S. Zhu, K. Ishihara, J. L. Brash, Langmuir, 21, 5980 (2005)

[21] C. Quek, J. Li, T. Sun, M. L. Hou Chan, H. Mao, L. M. Gan, K. W. Leong, H. Yu, Biomaterials, 25, 3531 (2004)

[22] J. Yamaguchi, J. Watanabe, M. Takai, K. Ishihara, Trans. Mater. Res. Soc. Jpn., 30[4] $1081-1084$ (2005)

[23] J. Yamaguchi, J. Watanabe, M. Takai, K. Ishihara, J. Appl. Polym. Sci., 104, 44 (2007)

[24] K. Ishihara, T. Ueda, N. Nakabayashi, Polym $J, 22,355-360$ (1990).

[25] A. V. Rami Reddy, K. Subramanian, A. V. Sesha Sainath, J. Appl. Polym. Sci., 70. 2111 2120 (1998)

(Received December 9, 2006;Accepted April 11, 2007) 